\title{
Power conversion efficiency (PCE) performance of backilluminated DSSCs with different Pt catalyst contents at the optimized TiO2 thickness
}

\begin{abstract}
The Power Conversion Efficiency (PCE) of back illuminated dye sensitized solar cells (DSSCs) using Titanium Dioxide (TiO2) printed on Titanium foil photo-anode was investigated. It is essential to study the optimum volume of the Platinum (Pt) catalyst solution spin-coated on counter electrode and the $\mathrm{TiO} 2$ absorbance layer optimized thickness for optimum light harvesting in a back illuminated structure. In this study, we have concentrated on the optimized $11 \mu \mathrm{m}$ thick of $\mathrm{TiO} 2$ film assembled on the photoanode using Doctor Blade printing method. The $11 \mu \mathrm{m}$ thick films were tested in a constraint of Platinum contents obtainable from $30 \mu \mathrm{l}, 50 \mu \mathrm{l}$ and $70 \mu \mathrm{l}$ volumes of Pt solutions. The same cells were also subjected to front illumination to compare the results. The back illuminated optimization was achieved with the $11 \mu \mathrm{m} \mathrm{TiO} 2$ film thickness which was at $\mathrm{PCE}=2.99 \%, \mathrm{Jsc}=7.83 \mathrm{~mA} / \mathrm{cm} 2$, $\mathrm{Voc}=0.7 \mathrm{~V}, \mathrm{FF}=0.55$ with the minimum volume of the Pt solution. From the selected ideal thickness of $11 \mu \mathrm{m} \mathrm{TiO} 2$ film performances of the Fluorine Tin Oxide (FTO) glass as solid state photoanode during back illumination, a similar methodological structure was imposed on Titanium foil based anode cells where the achievement was indicated at PCE $=2.75 \%$, $\mathrm{Jsc}=4.62 \mathrm{~mA} / \mathrm{cm} 2, \mathrm{Voc}=0.71 \mathrm{~V}, \mathrm{FF}=0.84$ for a $70 \mu \mathrm{l}$ volume of Pt solution. The results show that for a solid state photoanode substrate, $30 \mu \mathrm{l}$ of $\mathrm{Pt}$ solution is sufficient to provide catalytic activities and at the same time allow light penetration to the active region, whereas the flexible photoanode requires a higher concentration of Pt solution for rapid catalytic capabilities.
\end{abstract}

Keyword: Back illuminated; Dye sensitized solar cells (DSSCs); TiO2; Titanium foil; Front illuminated 